\title{
Nova Cartografia Social e Geotecnologias aplicadas a gestão territorial de comunidades tradicionais
}

\section{New Social Cartography and Geotechnologies applied to the territorial management of traditional communities}

\author{
Matheus Vinicius Ferreira \\ Mestrando em Geografia pelo PPGEO-Programa de Pós-Graduação em Geografia \\ UNIMONTES, Brasil \\ mmatheusvf@gmail.com \\ Marcos Esdras Leite \\ Doutor em Geografia -Professor do Departamento de Geociências \\ NIMONTES, Brasil \\ marcosesdrasleite@gmail.com
}

Sérgio Leandro Sousa Neves

Doutor em Geografia -Professor do Instituto Federal do Norte de Minas Gerais - IFNMG,

Diamantina-MG, Brasil

sergio.neves@ifnmg.edu.br

\begin{abstract}
Resumo
Os povos e comunidades tradicionais do Brasil enfrentam diversos problemas relacionados a posse e gestão territorial. Essa parcela da população pode encontrar na Cartografia ferramentas que as auxiliem nessa luta. Essas ferramentas cartográficas, que abarcam as geotecnologias e o automapeamento, são pouco utilizadas de forma integrada. Explorou-se aqui, o potencial da aplicação conjunta do mapa social com as Geotecnologias no processo de gestão territorial para comunidades tradicionais. Baseou-se na análise da experiência de automapeamento realizada na Comunidade Buriti do Meio, no norte de Minas Gerais, pelo projeto Nova Cartografia Social da Amazônia, bem como no mapeamento de uso e cobertura da terra da comunidade. Com a associação dos dois produtos foi possível reafirmar a situação conflituosa vivenciada pela comunidade com fazendeiros vizinhos. É urgente a regularização do processo de demarcação territorial da comunidade quilombola Buriti do Meio, já aberto pelo INCRA em 2005, para que possam sobreviver e manter seu modo de vida tradicional.
\end{abstract}

Palavras-chave: Uso da Terra; Quilombo; Automapeamento; Território.

\begin{abstract}
The traditional peoples and communities of Brazil face several problems related to land tenure and management. This portion of the population can find in Cartography tools to assist them in this struggle. These cartographic tools, which include geotechnologies and automation, are little used in an integrated manner. It explored here the potential of the joint application of the social map with Geotechnologies in the territorial management process for traditional communities. It was based on the analysis of the automation experience carried out in the Buriti do Meio Community, in the north of Minas Gerais, by the New Social Cartography of the Amazon project, and the mapping of land use and coverage of the community. With the association of the two products, it was possible to reaffirm the conflictive situation experienced by the community with neighbouring farmers. It is urgent to regularize the process of territorial demarcation of the quilombola community Buriti do Meio, already opened by INCRA in 2005, to survive and maintain their traditional way of life.
\end{abstract}

Keywords: Land use; Quilombo; Automation; Territory. 


\section{INTRODUÇÃO}

A Cartografia, desde sua gênese tem por objetivo a representação dos espaços e das relações sociais por meio de estruturas abstratas. No devir histórico sua utilização foi associada à legitimação, conquista e gestão de territórios. A prática cartográfica com esta finalidade sempre esteve sob posse do Estado ou de Organizações poderosas, que utilizavam a cartografia para estratégias de domínio territorial pouco vantajosas para os grupos minoritários (ACSELRAD, 2008; MARTINELLI 2009). De tal forma, o uso desse instrumento deve contemplar no tempo e no espaço as nuances contrastantes, principalmente àquelas que compreendam os grupos minoritários. Com o advento das tecnologias, sobretudo de informação espaço temporal, bem como o aumento da visibilidade de movimentos e organizações sociais, surgem na Cartografia propostas de mapeamentos que contemplam a territorialidade de grupos que podem participar de forma autônoma do processo de apreensão e representação de seus territórios.

Dentre esses grupos encontram-se os povos e comunidades tradicionais, que representam uma parcela da sociedade de grande importância histórica, que têm seus modos de vidas intimamente ligados a utilização dos territórios e dos recursos naturais neles presentes (BRASIL, 2007). No Brasil esses grupos enfrentam uma série de problemas relacionados a disputas territoriais, como a sobreposição de seus territórios com outros que não são tradicionais, o impedimento de acessar os recursos naturais e dificuldades com regularização da terra, figurando em muitos casos situações de conflitos que raramente são solucionados (ROSSI, 2016).

$\mathrm{Na}$ busca pela mitigação desses problemas, as comunidades tradicionais, bem como a sociedade civil passaram a se articular e se organizar de forma a reivindicar o cumprimento de seus direitos garantidos pela constituição (ROSSI, 2016; SOARES, 2019). Um exemplo de articulação e parceria firmada entre organizações internas de comunidades tradicionais e a sociedade civil, são os projetos de pesquisa realizados por instituições de ensino, que dão visibilidade e voz a esses grupos. Nesse âmbito, encontra-se o Projeto Brasil Central, que é uma iniciativa vinculada a Universidade Estadual do Maranhão - UEMA, juntamente com outras 10 Universidades localizadas em nove estados do Brasil, entre elas a Universidade Estadual de Montes Claros - Unimontes. O projeto que é filiado ao PNCSA - Projeto Nova Cartografia Social da Amazônia, desenvolve uma série de atividades voltadas para o mapeamento social de povos e comunidades tradicionais, dentre elas a comunidade quilombola Buriti do Meio, localizada no município de São Francisco, norte de Minas Gerais.

Tanto no âmbito nacional quanto internacional, pesquisadores tem utilizado da autocartografia, sobretudo dos mapas colaborativos, cartografia social e Nova Cartografia Social para identificar demandas comunitárias, evidenciar situações de conflitos ambientais e agrários 
vivenciadas por comunidades que habitam territórios tradicionais (RODRIGUES et al., 2017; OLIVEIRA 2019; COLLA, 2020; NASCIMENTO, 2020; PELEGRINA, 2020).

As geotecnologias, especialmente o sensoriamento remoto, tem subsidiado monitoramentos e informações espaciais de grande relevância para diagnósticos e tomadas de decisões de povos e comunidades tradicionais acerca de seus territórios (FERNANDES; PIMENTEL, 2019; VIANA; CAZULA, 2019; PEREIRA; OLIVEIRA; FARIA, 2020).

A integração dessas duas metodologias cartográficas, até o presente momento, foram pouco exploradas, e visando abordar essa lacuna nas pesquisas, propõe-se analisar o potencial da aplicação conjunta da Nova Cartografia Social com as Geotecnologias, no processo de gestão territorial para comunidades tradicionais. Para este fim, foi utilizado a experiência de autocartografia realizada na Comunidade Buriti do Meio, no norte de Minas Gerais, bem como o mapeamento de uso e cobertura da terra deste mesmo território. Essa análise poderá auxiliar em estratégias de reivindicações de direitos territoriais por parte de comunidades tradicionais que, apesar de terem suas garantias firmadas em aparatos legais, enfrentam dificuldades em dialogar com o poder público e colocar em prática esses direitos.

\section{METODOLOGIA}

\subsection{Caracterização da área de estudo}

A comunidade quilombola Buriti do Meio localiza-se entre as coordenadas $16^{\circ} 7^{\prime} 0^{\prime \prime} \mathrm{S}$ e

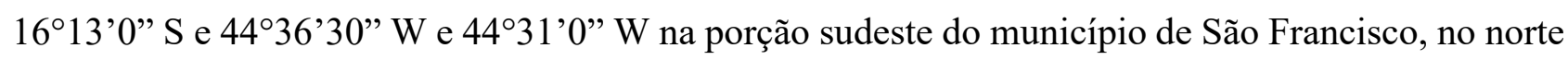
de Minas Gerais, a cerca de $30 \mathrm{~km}$ da sede municipal, limítrofe com o município de Luislândia. Judicialmente ainda não existe uma demarcação declarando os limites oficiais do território, impossibilitando desta forma o levantamento da área da comunidade.

Por meio de informações obtidas na experiência de automapeamento do Projeto Nova Cartografia Social, foi possível identificar a atual área de incidência da comunidade, bem como uma área estimada do território histórico (Figura 1). Atualmente vivem na área de incidência da comunidade cerca de 270 famílias.

O clima da região é caracterizado pelo tipo sub-úmido aproximando-se do sub-úmido seco, no qual as chuvas se concentram entre os meses de outubro a março, e o período seco se apresenta principalmente nos meses de junho a agosto (NIMER; BRANDÃO, 1989). Em relação as características geológicas, a área de estudo está localizada no grupo Bambuí sob as formações Lagoa do Jacaré e Serra da Saudade, com predominância de rochas sedimentares (CODEMIG, 2013). São encontrados na área, os solos Latossolo Vermelho-Amarelo, Neossolo Quartzarenico Ortico, Cambissolo Háplico, Argissolo Vermelho-Amarelo e Neossolo Litólico (UFV, 2010). Os aspectos 
biogeográficos da comunidade são marcados por fitofisionomias do Cerrado Sentido Restrito, Floresta Estacional Decidual e a Mata Ciliar (BORGES, 2018).

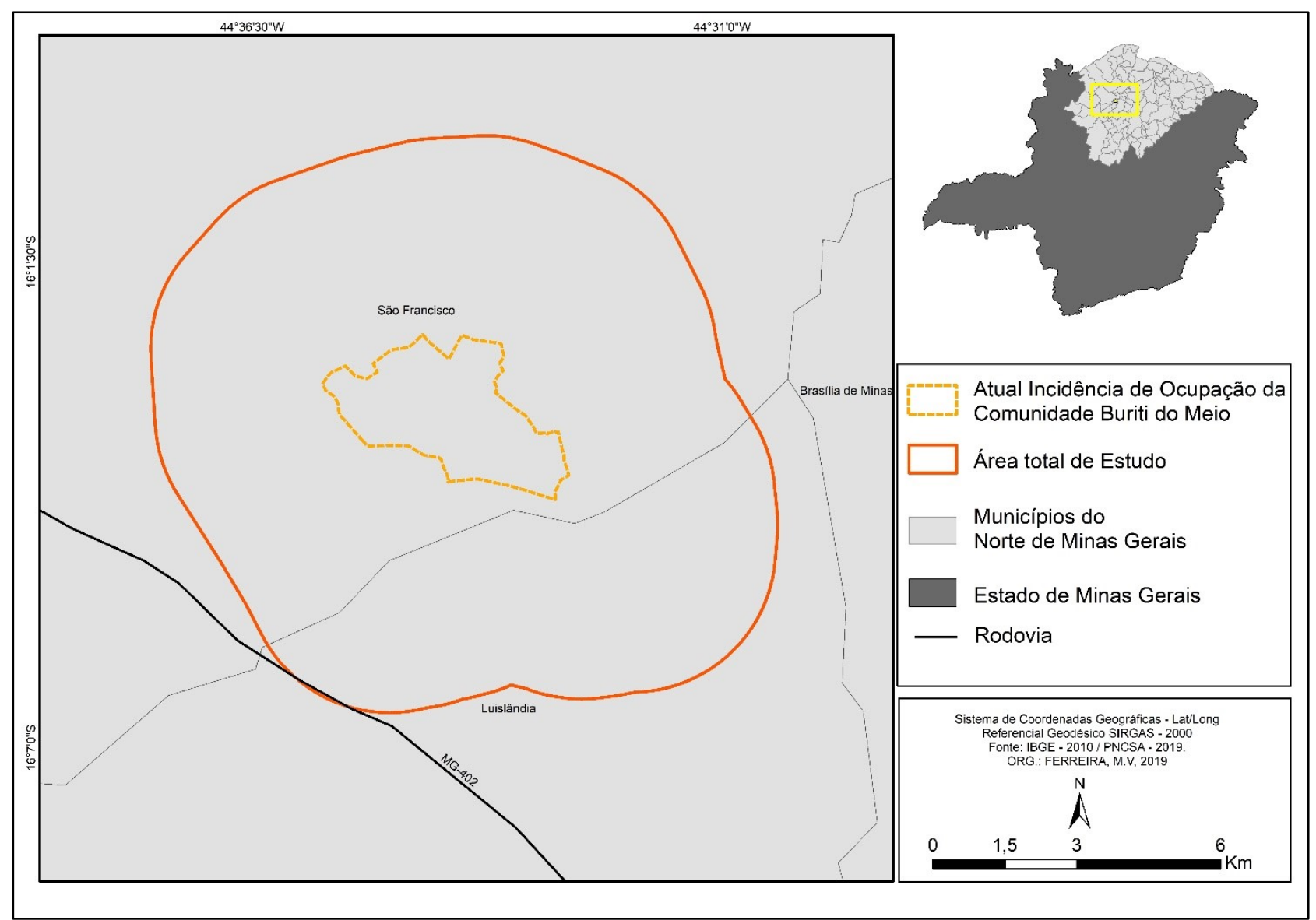

Figura 1 - Localização da comunidade Buriti do Meio, Norte de Minas Gerais.

\subsection{Procedimentos Técnicos e Operacionais}

Para execução dessa pesquisa seguiu-se procedimentos técnicos operacionais integrados considerando as etapas de campo em conjunto com os moradores da comunidade quilombola, buscando validação dos dados (Figura 2).

Inicialmente foi realizada uma revisão bibliográfica, de autores que abordam os temas da pesquisa. Posteriormente, foram adquiridos documentos cartográficos, depoimentos, imagens, mapa e informações acerca da experiência de mapeamento social na comunidade Buriti do Meio, com o núcleo da Unimontes do Projeto de Pesquisa Brasil Central / Nova Cartografia Social da Amazônia - PNCSA.

Quanto aos procedimentos técnicos e operacionais, foram obtidas imagens dos satélites Landsat 5 e 8, dos sensores TM e OLI, correspondentes à órbita/ponto 219/71 (USGS - United States Geological Survey). Esses produtos são referentes as seguintes datas: 16/06/1985; 12/06/1995; 09/07/2005 e 30/08/2018. Todas elas pertencem ao período de inverno, visto que nesta época não 
houve presença de nuvens ( 0 a $9 \%$ de cobertura de nuvens) no momento da passagem do sensor, o que favoreceu o processo de fotointerpretação.

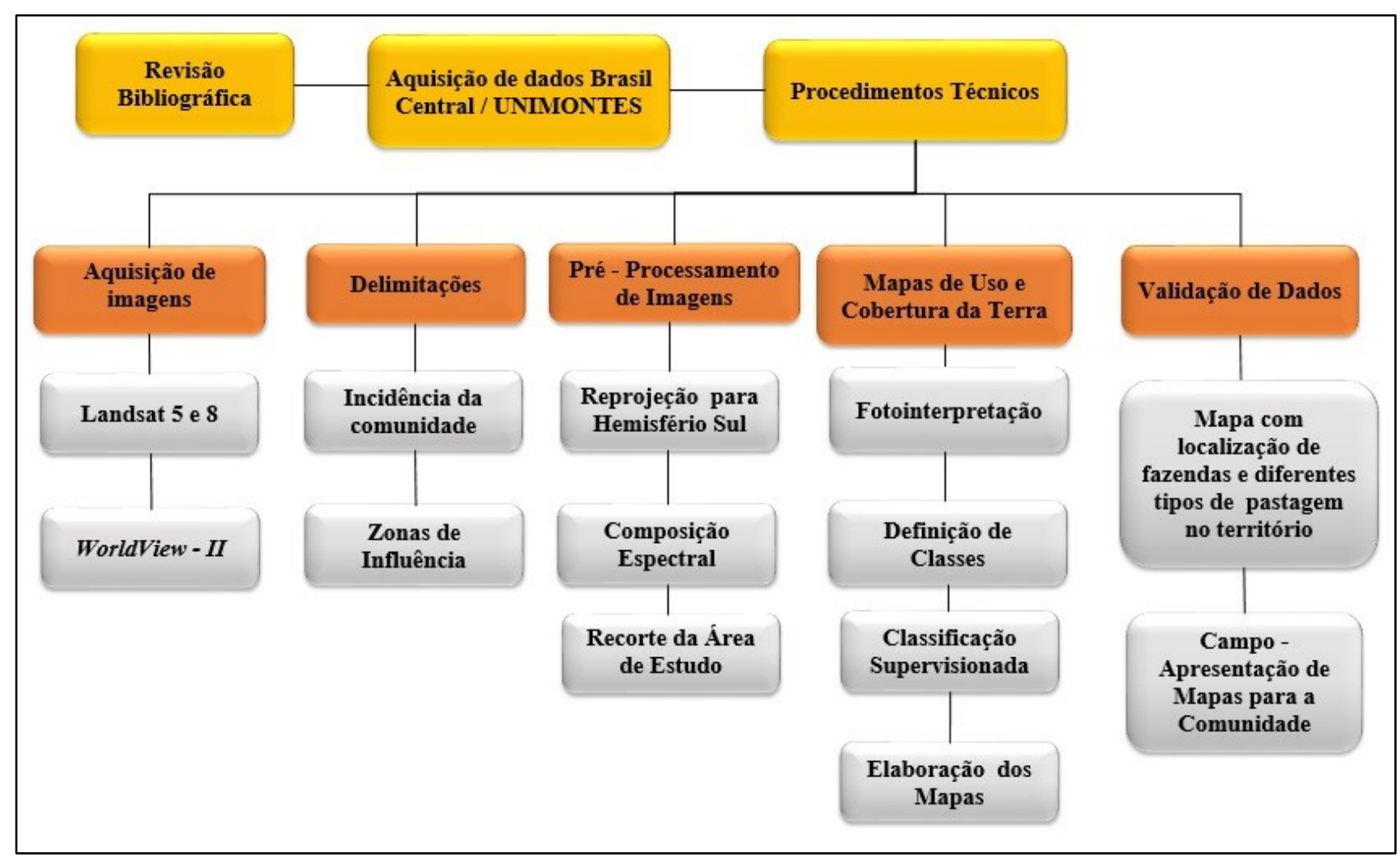

Figura 2 - Descrição dos procedimentos metodológicos.

Fonte: Os autores.

Em seguida, foi delimitada a atual área de incidência da comunidade, com base nas informações adquiridas anteriormente (Mapa PNCSA, relatos da comunidade e waypoints), a partir dessa delimitação foram produzidas zonas de influência em raios de 1, 3 e $5 \mathrm{~km}$, com a ferramenta Buffer da plataforma ArcMap do software ArcGis. Estas delimitações foram importantes para análise espaço-temporal da dinâmica de uso e cobertura da terra.

Posteriormente, foi realizado no software ERDAS o pré-processamento das imagens de satélite, com os procedimentos de re-projeção e composição espectral. Em seguida, com a ferramenta clip, no ArcMap realizou-se recorte nas imagens, delimitando a área total de estudo com o arquivo buffer de influência de $5 \mathrm{~km}$. Com as imagens processadas e recortadas iniciou-se no software ERDAS o procedimento de Classificação Supervisionada para confecção dos mapas de Uso e Cobertura da Terra, no qual teve como primeiro passo a definição das classes, por meio de técnica de interpretação visual (Fotointerpretação): Vegetação Nativa, Pastagem e Monocultura. A classe pastagem refere-se às áreas destinadas a pecuária de animais de médio e pequeno porte (IBGE,2013), admitindo-se também a presença de áreas de solo exposto, cultivos e edificações, uma vez que a resolução espacial 
(900 $\mathrm{m}^{2}$ por pixel) das imagens utilizadas no mapeamento, inviabiliza a segregação desses elementos em classes distintas.

Após o estabelecimento das classes foi feita coleta de amostras nas imagens, para obtenção de assinatura espectral dos alvos. Com a entrada da assinatura espectral na ferramenta supervised classification do software ERDAS foi gerada a classificação supervisionada das imagens por meio do algoritmo Maxver (máxima verossimilhança). Para auxiliar na coleta das amostras, utilizou-se a imagem de alta resolução do satélite WorldView-II referente ao ano de 2015.

A fim de observar a disposição espacial das propriedades rurais no território, bem como analisar os diferentes usos compreendidos na classe pastagem, foi elaborado um mapa, utilizando como base de dados o acervo fundiário do INCRA - Instituto Nacional de Colonização e Reforma Agrária, dados do PNCSA, além do mosaico de imagens de alta resolução basemap.

Em campo foi realizado uma validação dos mapas de Uso e Cobertura da Terra, a partir de apresentação dos resultados para moradores da comunidade Buriti do Meio. Este procedimento se baseou na confiabilidade e respeito pela experiência de vida destes moradores, que tendo notável conhecimento histórico e empírico acerca de seu território e de sua dinâmica de ocupação tiveram a capacidade de interpretar a representação cartográfica e avaliar o quão fiel à realidade ela estava.

\section{RESULTADOS E DISCUSSÃO}

\subsection{O contexto da Comunidade Quilombola Buriti do Meio e a Experiência PNCSA}

As raízes da comunidade Buriti do Meio remontam ao século XIX, período em que um escravo fugido da Bahia, denominado Euzébio Gramacho Gonçalves decidiu se fixar nas terras que atualmente são habitadas, em parte, por seus descendentes. Euzébio se casou com Emanuela Francisca de Barros e constituíram uma família que com o passar do tempo se expandiu a partir da união entre os filhos de Euzébio com moradores de comunidades próximas, e os sucessores dessas uniões casando-se primos com primos (AGUIAR, 2016; COSTA, 2016).

No devir histórico, o território Buriti do Meio foi transformado e a identidade do grupo construída de acordo a sua expansão. A utilização dos recursos naturais pela comunidade no seu modo de reprodução social se constitui em um elemento importante na transformação do espaço. Atividades como a agricultura (plantações de algodão, milho, feijão, mamona, mandioca, entre outros), coleta de alimentos e extração de barro para confecção de artesanato, eram essenciais para a sobrevivência da população. Essas atividades eram realizadas de forma coletiva, caracterizando um modo de vida baseado na solidariedade e na troca com o ambiente natural (RODRIGUES, 2013; AGUIAR, 2016).

Devido a existência de laços de parentescos consanguíneos entre os habitantes e de uma identidade baseada na coletividade, o território Buriti do Meio foi construído de forma livre e com 
ausência de cercas ou limites. A agricultura realizava-se pelas famílias em seus quintais, porém sem limitar os espaços; da mesma forma a criação de gado era realizada "na solta" em áreas de chapadas. As cercas começaram a surgir no território devido a aproximação do gado de fazendas vizinhas, como relata uma moradora da comunidade:

(Os fazendeiros) criavam gado, que eu lembro... Que eu sou das mais novas, mas eu lembro... Agora é que nós temos cerca de arame... Mas a comunidade, o pessoal daqui não tinham cerca, então os fazendeiros tinham os gados e muito das vezes eles soltavam os gados lá e vinham aqui pra beber água e as águas estavam tudo aqui dentro... No eles vir beber água comiam até plantação que os quilombolas plantavam. Igual nessa época de chuva assim, plantavam e vinham os gados pra beber água e acabava... (Tânia, 37 anos, entrevista cedida ao Projeto Brasil Central/Unimontes, 2017)

A partir desta imposição, a territorialidade da comunidade foi afetada, na medida em que a presença destas cercas provocou a segregação dos espaços internos, interferindo diretamente na identidade coletiva que foi construída ao longo do tempo. Além das limitações internas, outro grave problema originado pela presença das fazendas, refere-se a expropriação de parte do território, que foi acontecendo na medida em que os donos de propriedades vizinhas começaram a cercar e tomar para si áreas pertencentes a comunidade Buriti do Meio.

O pessoal de antigamente tinham as terras de plantar, mas eles (os fazendeiros) pegavam e tomavam e assentavam e ficavam para eles. Eu lembro que meu pai, ele se revoltou, ele disse que ele tinha terra muito boa mesmo e foi tomado tudo por eles e aí nós ficamos sem nada, que foi aonde nós viemos tudo pra esse lugarzinho aqui, próximo de Buriti, Imbu (Honorinda, 67 anos e Nilda, 53 anos, entrevista cedida ao Projeto Brasil Central/Unimontes, 2017)

O relato demonstra que o avanço das fazendas sobre o território quilombola é um problema originado desde as últimas gerações, obrigando a comunidade - que vem crescendo demograficamente - a se concentrar em determinadas áreas, dificultando a realização de atividades necessárias à sua sobrevivência, como a agricultura.

Situações conflituosas envolvendo a apropriação indevida de terras ocupadas por comunidades tradicionais são recorrentes no Brasil, como ocorre no território Kalunga, maior quilombo do país, localizado no estado de Goiás, que vivencia problemas relacionados tanto com a complexa regularização fundiária (que gerou, inclusive, conflitos internos) quanto com a resistência ao processo de desintrusão, por parte de fazendeiros que residem de forma ilegal no território. (OLIVEIRA, 2017).

Outro exemplo de conflito entre fazendeiros e quilombolas é apontado por Brito (2018), que aborda a situação do Território Tradicional Sesmaria do Jardim, no estado do Maranhão. O território que é composto pelas comunidades Bom Jesus, São Caetano e Patos, se assemelha com a situação atual e histórica da Comunidade Buriti do Meio na medida em que ambas passaram pelo processo de 
imposição de cercas no território por parte de fazendeiros, que desta forma afetou o modo de vida baseado no uso coletivo, da comunidade.

No norte de Minas Gerais, além da comunidade Buriti do Meio figuram muitas outras disputas territoriais no âmbito de terras tradicionalmente ocupadas, e tais conflitos enfrentam dificuldades de solução mesmo adentrando no campo jurídico. Desta forma, emergem em meio aos morosos processos burocráticos e judiciais, inciativas de resistência e articulação por parte das comunidades tradicionais e da sociedade civil, a fim de buscar alternativas de enfrentamento aos problemas territoriais e garantir o cumprimento de seus direitos resguardados constitucionalmente (ROSSI, 2016; SOARES, 2019).

Uma dessas iniciativas diz respeito a parceria estabelecida entre a comunidade Buriti do Meio e o Núcleo Interdisciplinar de Investigação Socioambiental (NIISA), juntamente com o Programa de Pós Graduação em Desenvolvimento Social (PPGDS), vinculados a Universidade Estadual de Montes Claros, que culminou na inserção da comunidade quilombola no Projeto Conflitos Sociais e Desenvolvimento sustentável no Brasil Central, coordenado pela UEMA Universidade Estadual do Maranhão.

A experiência de construção do mapa social da comunidade Buriti do Meio seguiu os moldes propostos na metodologia do Brasil Central / PNCSA, visto que prioriza a autonomia dos sujeitos autóctones no processo cartográfico, na qual a figura dos pesquisadores assume a função de coadjuvante, restringindo suas atividades à orientações técnicas e organização final do fascículo.

Foram realizadas oficinas de capacitação, na qual os pesquisadores apresentaram conceitos importantes da cartografia, bem como instrumentos das geotecnologias como o receptor GPS, para a comunidade. Em seguida, foram realizadas as oficinas de cartografia, momento em que a comunidade recebeu total liberdade para expressar e representar seu território e suas territorialidade específicas por meio do desenho de um croqui.

A partir do croqui, foram realizados procedimentos técnicos para produção do mapa que compôs o fascículo, produto do projeto. Foram utilizados waypoints (pontos coletados com receptor GPS), obtidos pela comunidade, dos locais e alvos representados no croqui, para georreferenciamento destes elementos, bem como os desenhos dos ícones para composição da legenda.

Após a construção do mapa (Figura 3) foi realizado um penúltimo campo, a fim de validar as informações contidas no produto e assegurar a fidelidade da representação técnica do território em relação a produção construída pela comunidade.

No mapa (Figura 3) foram apresentados por meio de ícones e símbolos, diversas localidades, recursos naturais, estradas e acessos, e os marcos históricos, que na perspectiva da comunidade são elementos essenciais na composição do território quilombola. Elementos externos ao território atual, mas que representam conflitos históricos relacionados a disputa territorial, como as fazendas e cercas, 
também foram representados no mapa pela comunidade, demonstrando preocupação com a defesa e gestão do território.

As fazendas foram representadas no mapa em sete ícones de residências que circundam o território, que nitidamente manifestam o encurralamento ${ }^{1}$ da comunidade por essas propriedades. Apesar de não existir um contexto de violência e ameaças nos conflitos com os fazendeiros, a presença das fazendas e a diminuição do território quilombola é uma das principais inquietações da comunidade.

Inclusive essas duas fazendas que trabalhei, elas estão em terras que antes faziam parte de Buriti... Porque meu pai falava né, do lugar onde era o marco da divisa de lá pra lá e de cá, que pertence a Buriti do Meio... Esse marco fica lá na Fazenda de Passagem Funda, da fazenda pra cá pertence a Buriti do Meio... Eles marcaram, só que essas marcas lá acho que não existem mais não, é o que Rodrigo acabou de falar tem o lugar que eles marcaram, mas acabou o pessoal colocou fogo nas mangas e queimou os marcos tudo, mas eles mesmos sabe onde que é, eu mesmo não sei direito não, porque eu sei que meu pai falava né, que tinha os lugares, as divisas da Passagem Funda pra cá, tudo é Buriti do Meio. Eles foram colocando cercas né... (Maria de Lourdes, 59 anos, entrevista cedida ao Projeto Brasil Central/Unimontes, 2017)

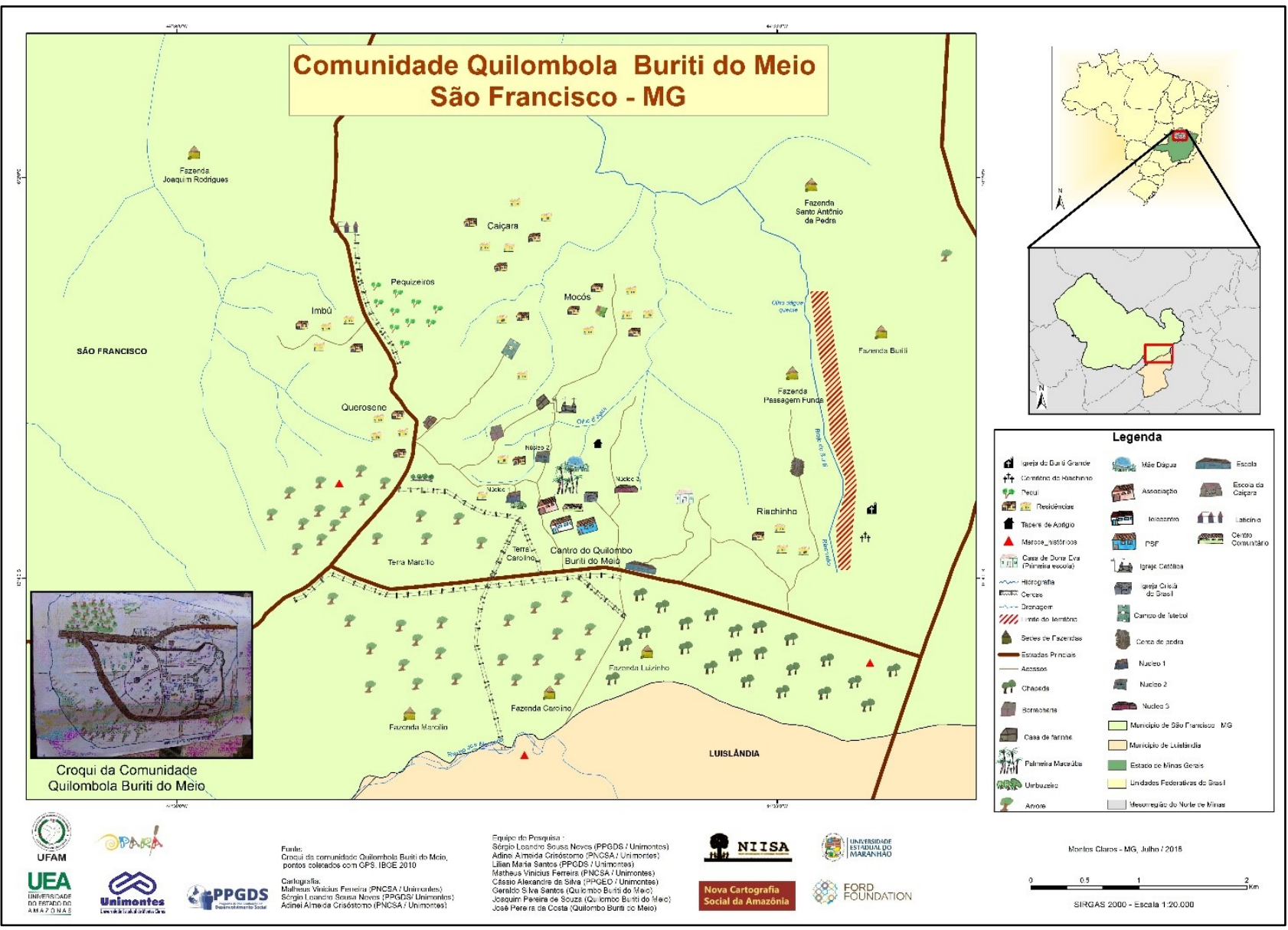

Figura 3 - Mapa produzido a partir de croqui, confeccionado pela comunidade Buriti do Meio.

\footnotetext{
${ }^{1}$ Denominação nativa do norte de Minas Gerais, que remete a sobreposição de territórios. Esse processo teve início ainda no período colonial com as implementação de fazendas na região, e essa ocupação se intensificou nas décadas de 1930 e 1940, levando a expropriação de diversas comunidades tradicionais e ocasionando conflitos desde então (ANAYA, 2014).
} 
O depoimento da moradora sintetiza a preocupação reproduzida no mapa por meio dos símbolos e desenhos. Inclusive, atenta para a destruição dos marcos históricos, que mesmo não existindo mais no espaço real estão inseridos na representação cartográfica, pois é um elemento ainda presente na memória da população.

Após finalizado o fascículo, foi realizado o último campo à comunidade, com o objetivo de entregar o produto material para aqueles que foram os protagonistas da experiência. Em meio a cerimônia de entrega, a partir de relatos de lideranças, registrou-se o primeiro resultado imediato do Mapa da Nova Cartografia Social para a comunidade e conquista de uma das reivindicações. O mapa serviu de documento geográfico comprobatório do território para a instalação de energia elétrica pela Companhia Energética de Minas Gerais - CEMIG, para cerca de 80 famílias que ainda não usufruíam deste recurso.

A metodologia de autocartografia foi aplicada com a preocupação em seguir as diretrizes do PNCSA, constatando-se assim, êxito em tais práticas desenvolvidas. No entanto, no que se refere ao levantamento de informações espaciais do território, a proposta do PNCSA pode apresentar limitações, na medida em que não é possível que se realize interferências externas no ato do mapeamento, excluindo desta forma, possíveis contribuições de metodologias e tecnologias, de análise espacial, por exemplo, que poderiam ampliar a visão da comunidade sobre seu próprio território e auxiliar na discussão da luta histórica pela terra.

\subsection{Análise Espaço-temporal do Uso e Cobertura da Terra}

O mapa de uso e cobertura da terra subsidiou um aprofundamento em questões pontuais da comunidade Buriti do Meio no âmbito das disputas territoriais, na medida em que a espacialização e quantificação dos usos no território, nas últimas três décadas, revelaram uma dinâmica de ocupação ora contrastante ora diretamente influenciada, entre a atual área de incidência da comunidade Buriti do Meio e as zonas de influência onde se concentram diversas propriedades rurais (Figura 4).

A Tabela 1 apresenta os valores de área para cada classe de uso e ocupação da terra nos períodos analisados, bem como sua distribuição nas áreas de análise do território. A área total do recorte espacial estudado é de $157 \mathrm{~km}^{2}$. No ano de 1985 verificou-se que a vegetação nativa ocupava uma área de $126,40 \mathrm{~km}^{2}$, o que corresponde aproximadamente a 80,51\% de toda a área de estudo. Em relação a classe pastagem, foram identificados $30,60 \mathrm{~km}^{2}$, ou seja, 19,49\% do território. Apesar da presença da classe pastagem ter sido observada nas quatro porções do recorte, salienta-se que na área de incidência da comunidade (IC) essa classe compreende principalmente atividades como pequenos cultivos; edificações e quintais. Por sua vez, nas zonas de influência (Z1, Z2 e Z3), onde se localizam propriedades rurais, é possível identificar predominância de áreas de pastagem para pecuária devido ao formato geométrico e extensão das feições. 


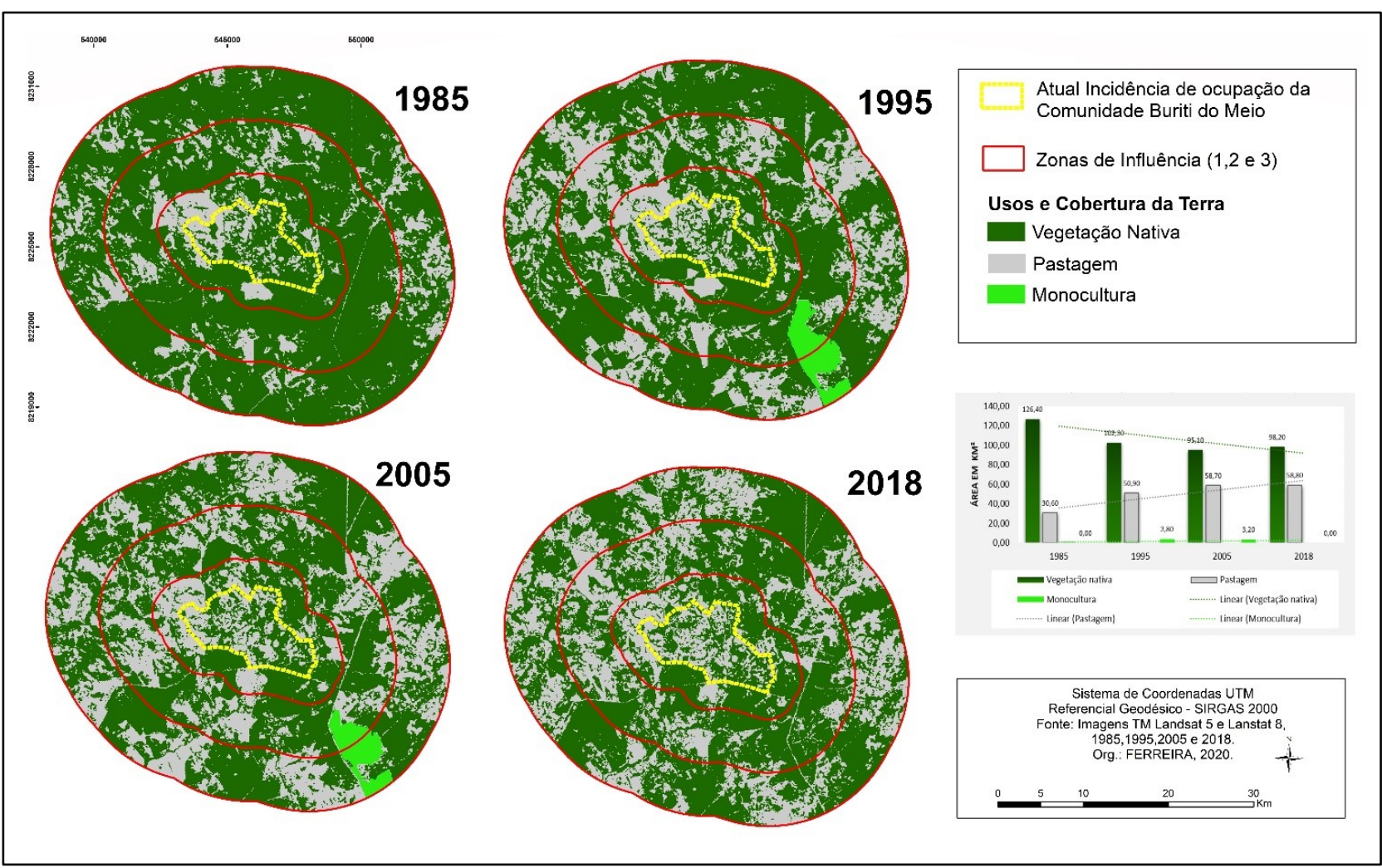

Figura 4 - Mapa temporal de uso e cobertura da terra da comunidade Buriti do Meio.

Tabela 1: Distribuição das áreas das classes de uso e cobertura da terra.

\begin{tabular}{|c|c|c|c|c|c|c|c|c|c|c|}
\hline \multirow{2}{*}{$\begin{array}{c}\text { Áreas } \\
\text { de } \\
\text { Análise }\end{array}$} & \multicolumn{2}{|c|}{1985} & \multicolumn{3}{|c|}{1995} & \multicolumn{3}{|c|}{2005} & \multicolumn{2}{|c|}{2018} \\
\hline & $\begin{array}{c}\text { Vegetação } \\
\text { Nativa } \\
\left(\mathrm{km}^{2}\right) \\
\end{array}$ & $\begin{array}{c}\text { Pastagem } \\
\left(\mathrm{km}^{2}\right)\end{array}$ & $\begin{array}{c}\text { Vegetação } \\
\text { Nativa } \\
\left(\mathrm{km}^{2}\right) \\
\end{array}$ & $\begin{array}{c}\text { Pastagem } \\
\left(\mathrm{km}^{2}\right)\end{array}$ & $\begin{array}{c}\text { Mono- } \\
\text { cultura } \\
\left(\mathrm{km}^{2}\right)\end{array}$ & $\begin{array}{c}\text { Vegetação } \\
\text { Nativa } \\
\left(\mathrm{km}^{2}\right)\end{array}$ & $\begin{array}{c}\text { Pastagem } \\
\left(\mathrm{km}^{2}\right)\end{array}$ & $\begin{array}{c}\text { Mono- } \\
\text { cultura } \\
\left(\mathrm{km}^{2}\right)\end{array}$ & $\begin{array}{c}\text { Vegetação } \\
\text { Nativa } \\
\left(\mathrm{km}^{2}\right)\end{array}$ & $\begin{array}{c}\text { Pastagem } \\
\left(\mathrm{km}^{2}\right)\end{array}$ \\
\hline IC & 6,12 & 3,29 & 5,44 & 3,97 & 0 & 5,06 & 4,35 & 0 & 4,84 & 4,57 \\
\hline $\mathrm{Z1}$ & 12,94 & 4,74 & 11,75 & 5,93 & 0 & 10,96 & 6,72 & 0 & 11,69 & 5,99 \\
\hline $\mathrm{Z} 2$ & 43,87 & 8,68 & 33,63 & 17,21 & 1,71 & 33,13 & 18,3 & 1,12 & 33,93 & 18,62 \\
\hline Z3 & 63,47 & 13,89 & 51,48 & 23,79 & 2,09 & 45,95 & 29,33 & 2,08 & 47,74 & 29,62 \\
\hline Total & 126,4 & 30,6 & 102,3 & 50,9 & 3,8 & $\mathbf{9 5 , 1}$ & 58,7 & 3,2 & 98,2 & 58,8 \\
\hline
\end{tabular}

Fonte: Os autores.

$\mathrm{Na}$ área de incidência da comunidade observou-se o menor valor de vegetação e o maior de pastagem (Tabela 1), denotando que já nesse período os recursos naturais utilizados tradicionalmente pela comunidade eram escassos, o que corrobora com os depoimentos de moradores da comunidade.

Ainda diante dos relatos, no qual os moradores mencionaram a imposição de cercas no território por parte dos fazendeiros e dessa forma o impedimento de acessar outras partes do território, é possível inferir que houve uma influência das áreas circunvizinhas sobre a área de incidência da comunidade, no qual os habitantes de Buriti do Meio foram obrigados a alterar seu modo de vida, se reorganizando territorialmente no pouco espaço que lhes restaram. Essa obrigatoriedade de reorganização territorial, e consequente comprometimento da reprodução do modo de vida de comunidades tradicionais é recorrente no norte de Minas Gerais, e suas causas ligadas a imposição 
da lógica de desenvolvimento capitalista, pautada no latifúndio, como observado em Rodrigues e Costa (2018) e em Neves, Leite e Neves (2020).

No período de 1995 , foi identificado um decréscimo na classe de vegetação nativa $(65,16 \%$ ou $102,30 \mathrm{~km}^{2}$ ), ao comparar com 1985. A pastagem, por sua vez, teve um acréscimo, representando $32 \%\left(50,90 \mathrm{~km}^{2}\right)$ do recorte espacial.

Observou-se neste ano (1995) o surgimento da classe monocultura que corresponde a 2,42\% $\left(3,80 \mathrm{~km}^{2}\right)$ do recorte estudado, e sua incidência se deu apenas nas zonas de influência 2 e 3 , onde se localiza uma propriedade rural. Esta área foi identificada, por moradores da comunidade, como reflorestamento de eucalipto. A produção dessa monocultura no norte de Minas teve sua expansão a partir da década de 1980, período em que a Superintendência de Desenvolvimento do Nordeste SUDENE, realizou uma série de investimentos econômicos e subsídios na região, entre eles a prática de reflorestamento para produção de carvão vegetal (LEITE, 2012). Segundo relatos da comunidade, a área de monocultura de Eucalipto identificada nesse ano foi utilizada para produção de carvão, e pertenceu ao grupo Plantar S/A.

Como apurado com a comunidade, devido a pouca oferta de trabalho na região muitos habitantes do quilombo trabalharam na área da monocultura, inclusive submetidos a superexploração e baixa remuneração. A exploração de mão de obra local na produção de carvão em áreas de reflorestamento, com condições precárias de trabalho, teve início no norte de Minas ainda na da década 60 e era uma prática comum dos proprietários de fazendas e empresas deste ramo, visando a maximização dos lucros, uma vez que se destinava baixos investimentos na infraestrutura, pagava-se remunerações muito baixas e impunha-se extensas jornadas de trabalho (RODRIGUES, 2013; SILVEIRA, 2014).

Ao analisar o recorte total estudado, percebe-se que as classes de uso antrópico avançaram sobre as áreas de vegetação nativa. A maior parte dessa mudança ocorre onde se localizam propriedades rurais (Figura 5), principalmente na porção noroeste e sudeste do território, dentro das áreas Z2 e Z3, que tiveram respectivamente perda de $10,24 \mathrm{~km}^{2}$ e $11,99 \mathrm{~km}^{2}$ de vegetação nativa $(92 \%$ da perda de vegetação nativa nesse período).

Em 2005 identificou-se a continuidade do comportamento das classes. A vegetação nativa decresceu para $95,10 \mathrm{~km}^{2}$ (60,57\%, aproximadamente, da área de estudo) e a área de pastagem elevou sua extensão para 58,70 $\mathrm{km}^{2}$ (aproximados 37,39\% do recorte espacial analisado). A classe Monocultura teve um leve decréscimo de $0,6 \mathrm{~km}^{2}$ passando a ter uma área de $3,20 \mathrm{~km}^{2}(2,04 \%$ do recorte espacial total). Nesse período dentre as áreas de influência analisadas, a Z3 teve a maior taxa de conversão de uso, com perda de $5,53 \mathrm{~km}^{2}$ de vegetação nativa.

Em 2018 foi observada regeneração de vegetação nativa, que passou a ter uma área de 98,20 $\mathrm{km}^{2}$ o que corresponde a $62,55 \%$ da área de estudo; pequeno acréscimo da área de pastagem, passando 
a equivaler $58,80 \mathrm{~km}^{2}$, o que corresponde a 37,45\% do recorte espacial. Com exceção da área de incidência da comunidade, todas as outras porções analisadas apresentaram regeneração de vegetação nativa, sendo que grande parte dessa conversão de uso deve-se ao encerramento das atividade de monocultura.

Segundo relatos de moradores da comunidade, o fim da monocultura pode ser associado com a elevação do custo de produção do carvão após o ano de 2005 e aumento de multas que a empresa passou a receber por estar em desacordo com as legislações ambientais, fato que inviabilizou a manutenção do negócio.

Em relação à exceção da área de incidência da comunidade na regeneração de vegetação nativa do território, percebe-se que o cenário observado em 1985, de relação desproporcional entre crescimento demográfico e disponibilidade de terra e recursos naturais, se manteve e se transformou em umas das principais preocupações da comunidade como demonstra o relato:

Eu queria, (o território) na verdade eu queria assim, que pelo menos que esses espaços que hoje estão cercados por essas fazendas que hoje não são utilizados, não são trabalhadas, que pelo menos esses espaços assim, que fosse né, (fizesse parte do território da comunidade) porque vai chegar dia que devido às famílias desenvolverem muito rápido, casam muito cedo e tem filho muito rápido, vai chegar dia que não vai ter mais condição de construir mais não, porque o quintal que a gente plantava, o filho constrói uma casa né, e os outros vão construindo, vai construindo e vai acabar que não vai ter espaço nenhum pra construir (...) (Maria de Lourdes, 59 anos, entrevista cedida ao projeto Brasil Central/Unimontes, 2017)

É possível observar a presença massiva de propriedades rurais no entorno da atual incidência da comunidade - tanto pela base de dados do INCRA, representada em polígonos, quanto pela base de dados do PNCSA que evidencia a localização de algumas sedes de fazendas - reafirmando as narrativas e informações apresentadas na experiência de automapeamento (Figura 5). O mapa ainda apresenta o contraste dos diferentes usos compreendidos na classe pastagem. Foi possível identificar elevada densidade de edificações e quintais, na área de incidência da comunidade, fato que corrobora com o depoimento apresentado anteriormente. Por sua vez, nas áreas circunvizinhas, onde se localizam propriedades rurais, notou-se grandes extensões de pasto e solo exposto, além de edificações isoladas que podem ser assumidas como sedes de fazendas.

Nota-se que o aparato das geotecnologias, sobretudo a análise espaço-temporal de uso e cobertura da terra, auxiliou no processo de visualização e reafirmação de situações-problemas no território Buriti do Meio. Outros trabalhos convergem para tais apontamentos, relacionando a efetividade das geotecnologias com as tomadas de decisões que envolvem a gestão territorial de comunidades tradicionais (RODRIGUES; SANTOS; PIMENTEL, 2016; FARIAS; OLIVEIRA; PEREIRA, 2019; GONÇALVES et al., 2019; NASCIMENTO et al., 2019) 


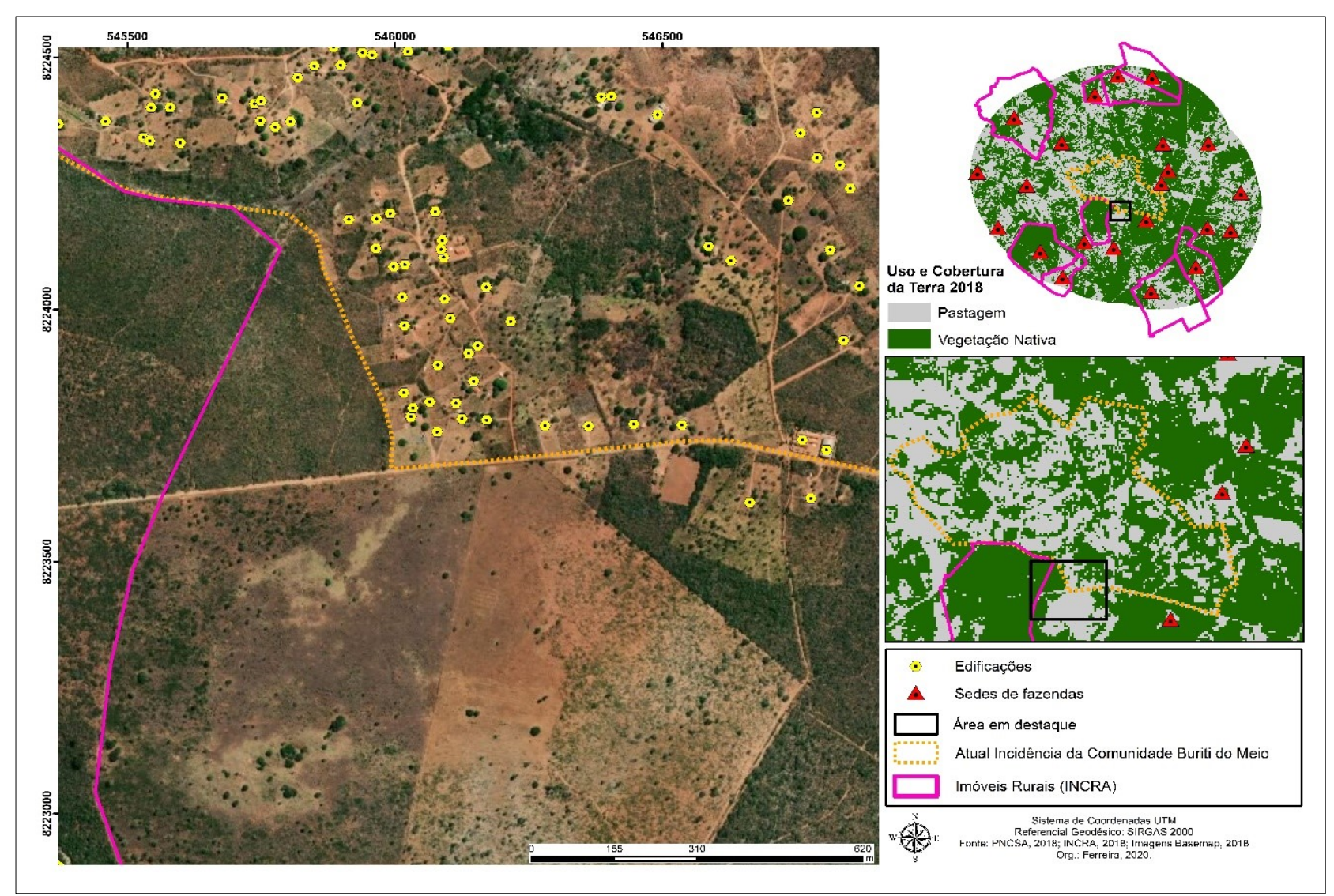

Figura 5 - Mapa de tipos de pastagens e localização de fazendas.

Fonte: Os autores.

Em relação a utilização de Geotecnologias e metodologias de mapeamentos participativos; Cartografia Social e afins, observa-se também na literatura, pesquisas que apontam para maior efetividade e precisão de resultados, quando aplicadas conjuntamente (FRANCO, RUCHKYS E DE DEUS, 2016; LINHARES E UMBELINO, 2017; AGUIAR, 2019). No caso específico da comunidade Buriti do Meio, nota-se que a associação dos dados da experiência PNCSA com os dados espaciais dos mapas de uso e cobertura da terra, se complementam e amenizam as limitações um do outro. O mapa social se destacou por contemplar as territorialidades especificas da comunidade, que não foram apreendidas no mapa de uso e ocupação da terra. Esse último, por sua vez, possibilitou análises espaço-temporais que não fazem parte do primeiro mapa, como a quantificação e evolução histórica da utilização dos recursos naturais presentes no território. Por fim, a complementação das metodologias corrobora para a urgência da regularização e demarcação do território quilombola.

O processo de titulação do território Buriti do Meio, aberto no ano de 2005 pelo Instituto Nacional de Colonização e Reforma Agrária - INCRA, encontra-se até o presente momento sem conclusão. Essa morosidade na conclusão de processos de demarcação de terras quilombolas é recorrente no Brasil e encontra situações semelhantes no norte de Minas Gerais, como aponta Rossi (2016). Entende-se dessa forma, que a utilização conjunta da Nova Cartografia Social e 
Geotecnologias pode vir a ser um instrumento paralelo na luta pelo direito à terra e consequentemente no resgate e manutenção do modo de vida da comunidade Buriti do Meio.

\section{CONSIDERAÇÕES FINAIS}

A experiência de mapeamento a partir de uma Nova Cartografia Social, realizada pelo Projeto Brasil Central na comunidade quilombola Buriti do Meio, proporcionou o levantamento de informações relevantes acerca do processo de ocupação territorial dessa comunidade, que vem enfrentando ao longo dos últimos anos problemas relacionados à disputa de terras e manutenção de seu modo de vida tradicional.

Com os resultados evidenciados no produto final do projeto, o fascículo e o mapa social, construído a partir da percepção dos sujeitos autóctones em relação a seu território, já foi possível colocar em prática reivindicações e conquistar direitos garantidos em lei, para a comunidade, como o acesso à energia elétrica, via CEMIG. Destaca-se desta forma a importância do mapa social como um instrumento de luta para as comunidades tradicionais que vivem muitas vezes na invisibilidade em relação a sociedade e poder público.

O mapa temporal de Uso e Cobertura da Terra confeccionado a partir de informações obtidas na experiência de mapeamento social e utilizando como aparato técnico e metodológico as Geotecnologias, por sua vez proporcionou a visualização e análise espacial da problemática da disputa territorial enfrentada pela comunidade, uma vez que foi possível observar a pressão das propriedades rurais sobre a área de incidência do quilombo. Foi identificado um decréscimo sistemático de vegetação nativa em todo o território ao longo dos 33 anos analisados, sendo que o uso da terra na área de incidência da comunidade pode ser relacionado com o crescimento demográfico da população que não tem mais acesso as terras historicamente utilizadas e desta forma são obrigadas a se concentrar em uma área encurralada por fazendas, ocasionando numa interferência na reprodução de seu modo de vida. Identificou-se também intensos usos de pastagem e monocultura aos longos dos períodos analisados, em áreas onde se localizam propriedades rurais dentro do território quilombola.

A utilização conjunta desses dois tipos de mapas, com metodologias de produção distintas, mas com finalidades semelhantes, pode se tornar uma importante estratégia de gestão territorial para comunidades tradicionais que buscam reconhecimento, visibilidade e justiça social. Acredita-se que que tais instrumentos podem ser utilizados na luta da comunidade Buriti do Meio pelo acesso a terra, que só será concedido a partir do processo de demarcação territorial iniciado pelo INCRA em 2005, e que somente com tal acesso aos recursos naturais a comunidade poderá retomar suas práticas tradicionais de reprodução social, essenciais para sua sobrevivência. 


\section{REFERÊNCIAS}

ACSELRAD, H. (Org.). Cartografias sociais e território. Rio de Janeiro: UFRJ/IPPUR, 2008. $168 \mathrm{p}$.

AGUIAR, V. G. Geotecnologias e a cartografia social para a representação de territórios em conflitos ambientais no norte do Tocantins. Escritas: Revista do Curso de História de Araguaína, v. 11, n. 1, p. 52-66, 2019.

AGUIAR, W. B. "Não tínhamos conhecimento nenhum": a voz ativa e política das mulheres quilombolas da comunidade Buriti do Meio - Norte de Minas Gerais. 2016. 139 f. Dissertação (Mestrado em Desenvolvimento Social) - Universidade Estadual de Montes Claros, Montes Claros, 2016.

ANAYA, F. C. "Vazanteiros em movimento": o processo de ambientalização de suas lutas territoriais no contexto das políticas de modernização ecológica. Ciência \& Saúde Coletiva, v. 19, n. 10, p. 4041-4050, 2014.

BORGES, M. G. Fitofisionomias do cerrado e as áreas potenciais de ocorrência do pequizeiro (Caryocar Brasiliense) e buritizeiro (Mauritia Flexuosa) no Norte de Minas Gerais. 2018. Dissertação (Mestrado em Geografia) - Universidade Estadual de Montes Claros, Montes Claros, 2018.

BRASIL. Decreto $\mathbf{n}^{\mathbf{0}}$. 6.040, de 7 de fevereiro de 2007. Institui a Política Nacional de Desenvolvimento Sustentável dos Povos e Comunidades Tradicionais. Brasília, 2007.

BRITO, C. S. Lugar de Conflitos: estudo de caso no Território Tradicional Sesmaria do Jardim, Baixada Maranhense. ACENO-Revista de Antropologia do Centro-Oeste, v. 4, n. 8, p. 109-126, 2018.

CODEMIG - Companhia de Desenvolvimento Econômico de Minas Gerais. Disponível em: < http://www.codemig.com.br/atuacao/mineracao/mapeamento-geologico/2013-mapa-geologico-deminas-gerais/ > Acesso em: 10 out. 2019.

COMUNIDADE QUILOMBOLA BURITI DO MEIO. Conflitos sociais e desenvolvimento Sustentável no Brasil central. n. 06. Coordenação da pesquisa: Andréa Maria Narciso Rocha de Paula. Manaus: UEA Edições / PNCSA, 2019.

COLLA, J. L. "Del otro lado del alambrado": conflictos territoriales y lucha por la tierra de los campesinos indígenas Qom en el Chaco argentino. Revista NERA, v. 23, n. 53, p. 166-192, 2020.

COSTA, L. P. "Migrantes Errantes" As travessias no quilombo Buriti do Meio. 2016. Monografia (Trabalho de Graduação em Ciências Sociais) - Universidade Estadual de Montes Claros, Montes Claros, 2016.

FARIAS, J. L. N.; OLIVEIRA, M. F.; PEREIRA, J. B. Dinâmicas de uso e cobertura do solo do território da comunidade pesqueira do povoado São Pedro, Jaramataia, Alagoas. Revista Verde de Agroecologia e Desenvolvimento Sustentável, v. 14, n. 5, p. 641-649, 2019.

FERNANDES, W. A. A.; PIMENTEL, M. A. S. Dinâmica da paisagem no entorno da Resex Marinha De São João Da Ponta. Caminhos de Geografia, v. 20, n. 72, p. 326-344, 2019. 
FRANCO, A. R.; RUCHKYS, Ú. A; DEUS, J. A. S. Mapeamento participativo e análise dos valores da geodiversidade com artesãos em pedra-sabão da região de Ouro Preto-Minas Gerais. Revista Brasileira de Cartografia, n. 68, p. 457-469, 2016.

GONÇALVES, D. C. M.; CORRÊA, J. A. J.; GAMA, J. R. V.; JÚNIOR, R. C. O. Análise da vegetação secundária em unidades de conservação: o uso de recursos florestais por comunidades tradicionais. Nature and Conservation, v. 12, n. 1, p. 1-9, 2019.

INCRA - Instituto Nacional de Colonização e Reforma Agrária. Acervo Fundiário. Disponível em: $<$ http://acervofundiario.incra.gov.br/acervo/acv.php >. Acesso em: 10 dez. 2019.

INSTITUTO BRASILEIRO DE GEOGRAFIA E ESTATÍSTICA(IBGE), Manual Técnico do uso da Terra. 2013. Disponível em:

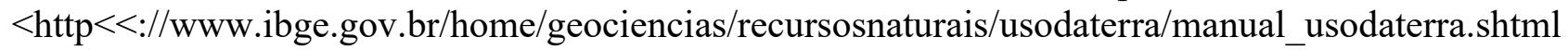
$>$. Acesso em: 25 nov. 2019.

LEITE, M. E.; ALMEIDA, J. W. L.; DA SILVA, R. F. Análise Espaço-Temporal do Eucalipto no Norte de Minas Gerais nos Anos de 1986, 1996 e 2010. GeoTextos, v. 8, n. 2, p. 59-74, 2012.

LINHARES, T. S.; UMBELINO, L. F. Mapeamento participativo: subsídio à gestão participativa e ao manejo sustentável de recursos naturais de comunidades tradicionais. Sociedade e Território, v. 29, n. 1, p. 50-70, 2017.

MARQUES, A. C. N. Dialogando sobre cartografia social e identidade em territórios tradicionais indígenas e quilombolas. Identidade!, v. 24, n. 2, p. 101-119, 2020.

MARTINELLI, M. Mapas da geografia e cartografia temática. 5. ed. São Paulo: Contexto, 2009. $144 \mathrm{p}$.

NASCIMENTO, J. E.; FÉ, E. G. M.; VIANA, L. J. M. Análise ambiental da cobertura e do uso da terra da Comunidade Quilombola Piqui da Rampa, município de Vargem Grande-MA. Brazilian Journal of Development, v. 5, n. 9, p. 16099-16113, 2019.

NEVES, S. L. S.; LEITE, M. E.; NEVES, L. V. R. F. A ascensão da agropecuária e seus reflexos sobre as estruturas socioespaciais de povos e comunidades tradicionais no médio São Francisco mineiro. Geosul, v. 35, n. 74, p. 333-350, 2020.

NIMER, E.; BRANDÃO, A. M. P. M. Balanço Hídrico e Clima da região dos Cerrados. Rio de Janeiro: IBGE, 1989.

OLIVEIRA, D.; TÁRREGA, M. C. Terra versus território: Pensar conflitos sobre territorialidades quilombolas a partir da realidade Kalunga. Revista da Faculdade de Direito da UFG, v. 41, n. 2, p. 219-236, 2017.

OLIVEIRA, T. R. Peixes, gentes e territórios tradicionais no Submédio e Baixo São Francisco: uma discussão com base na Nova Cartografia Social dos Povos e Comunidades Tradicionais do Brasil. Revista Ouricuri, v. 1, n. 1, p. 39-61, 2019.

OPARÁ - Projeto de Pesquisa: SUJEITO AGENTE - Pessoa Sertão: cultura popular e patrimônio cultural no Alto Médio São Francisco do Grupo de Estudos e Pesquisas sobre comunidades tradicionais do rio São Francisco. Comunidade Quilombo Buriti do Meio, nossos saberes. Unimontes, 2013. 
PELEGRINA, M. A. Cartografia social e uso de mapeamentos participativos na demarcação de terras indígenas: o caso da TI Porto Limoeiro-AM. Geousp - Espaço e Tempo, v. 24, n. 1, p. 136-152, 2020 .

PEREIRA, J. B.; OLIVEIRA, M. F.; FARIAS, J. L. N. Relações natureza e sociedade na classificação dos etnosolos na Colônia Z-29 em Jaramataia a partir de saberes tradicionais. Revista Craibeiras de Agroecologia, v. 5, n. 1, p. 9463, 2020.

RODRIGUES, M. H. S. G.; OLIVEIRA, J. S.; GOMES, M. S.; MERCURI, J.; SOUZA, P. D. C. Cartografia social no território do Parque Nacional Serra da Capivara-PI: mapeamento participativo para retomada da territorialidade. Revista CPC, n. 24, p. 56-77, 2017.

RODRIGUES, M. T. S. "Sertão de preto": Dinâmicas identitárias e territoriais na comunidade quilombola de Buriti do Meio. 2013. 78 f. Monografia (Trabalho de Graduação em Ciências Sociais) - Universidade Estadual de Montes Claros, Montes Claros, 2013.

RODRIGUES, M. T. S.; COSTA, J. B. A. Descolonizando os Gerais: situação colonial e estratégias de resistência das comunidades tradicionais geraizeiras do Norte de Minas Gerais. PerCursos, v. 19, n. 39, p. 77-103, 2018.

RODRIGUES, W. L. J.; SANTOS, V. C.; PIMENTEL, M. A. S. Geotecnologias e saberes tradicionais aplicados à análise espaço-temporal. Acta Geográfica, Ed. Esp., p. 27-43, 2016.

ROSSI, F. L. Conflitos envolvendo quilombolas em processos judiciais de Minas Gerais - Estudos de casos. Revista Jurídica, v. 4, n. 1, p. 1-24, 2016.

SILVEIRA, D. M. Comunidades Tradicionais do Norte de Minas: estratégias de luta e acesso a direitos territoriais. 2014. 151 f. Dissertação (Mestrado em Desenvolvimento Social) - Universidade Estadual de Montes Claros, Montes Claros, 2014.

SOARES, I. P. Conflitos socioambientais e a ameaça ao processo de demarcação de terras quilombolas no Brasil. Revista de Políticas Públicas, v. 22, n. 2, p. 687-709, 2019.

UFV - CETEC - UFLA - FEAM. Mapa de solos do Estado de Minas Gerais. Belo Horizonte, Fundação Estadual do Meio Ambiente, 2010. 49p. Disponível em: $<$ http://www.feam.br/noticias/1/949-mapas-de-solo-do-estado-de-minas-gerais > Acesso em: 11. out. 2019.

VIANA, I. G. S.; CAZULA, L. P. O Uso de geotecnologias para caracterização do desmatamento em áreas contíguas à Flona Tapajós-Pará1. Ciência Geográfica - Bauru, ano 23, v. 23, n. 1, p. 229-242, 2019. 